\title{
PENILAIAN KINERJA PERGURUAN TINGGI ISLAM DENGAN BALANCED SCORECARD AGAR TERWUJUD LEMBAGA PENDIDIKAN ISLAM BERBASIS MAQASID SYARIAH
}

\author{
Zuraidah \\ Esy Nur Aisayah \\ Maulana Malik Ibrahim State Islamic University of Malang \\ esynuraisyah@yahoo.com
}

\begin{abstract}
In improving organizational performance, alignment an organizations and individuals in the organization is very important. Balanced Scorecard is one of the alternative performance measure that aims to combine the performance measures of financial and non-financial. Inspired by Kaplan and Norton, the concept was developed in four perspectives: financial, customer, internal process and learning and growth. This article discusses how to build a balanced scorecard, include determining the strategic objectives, measures, targets, initiatives, and implementing the balanced scorecard in public organizations. The performance assessment of Islamic Universities have: 1) strategic targets financial perspective: the ability to obtain funding and cost efficiency, 2) strategic objectives perspectives of stakeholders, namely the satisfaction and pride for students, 3) strategic objectives of internal process perspective is a internal business portal, process and policy procedures, financial systems and reporting, internal control and performance measurement, research and community service quality, 4) strategic objectives of learning and growth perspectives improve the professionalism of human resources, improve the quality and infrastructure facilities. Islamic university has 21 strategic objectives in the four perspectives of the balanced scorecard. As well as the maqasid syariah used as an indicator both in aligning the results of an assessment of the performance of the Islamic universities.
\end{abstract}

Keywords: assessment; performance; balanced scorecard; maqasid sharia.

\section{PENDAHULUAN}

Perguruan Tinggi sebagai salah satu elemen dalam Sistem Pendidikan Nasional mempunyai tanggungjawab dalam mencerdaskan kehidupan bangsa dan mewujudkan visi Indonesia 2030 untuk menciptakan masyarakat yang maju, sejahtera, mandiri dan berdaya saing tinggi. Untuk mewujudkan masyarakat yang memiliki daya saing tinggi dalam kancah internasional. Perguruan Tinggi termasuk Perguruan Tinggi Agama Islam (PTAI) dituntut untuk menghasilkan lulusan yang berkualitas serta mampu memberikan tawaran solusi terhadap berbagai masalah kemanusiaan dan kebangsaan. Sementara itu terdapat berbagai tantangan organisasi untuk mewujudkan kinerja yang lebih baik, yang tidak hanya dituntut bagi sektor private, namun sektor public pun dituntut hal yang sama. Dalam menghadapi era global ini, maka keunggulan kompetitif di suatu negara terhadap negara lainnya adalah menjadi faktor penentu agar mampu bertahan, berperan, dan bersaing. Untuk melanggengkan keberadaannya, keunggulan kompetitif sebagai salah satu factor yang harus berkelanjutan (sustainable) karena pada dasarnya faktor ini akan melanggengkan keberadaannya. Keunggulan kompetitif berkelanjutan merupakan faktor perusahaan/organisasi untuk mencapai tujuan akhirnya, yaitu kinerja yang menghasilkan keuntungan (profit) tinggi. Artinya, keunggulan bersaing berkelanjutan bukanlah tujuan akhir, melainkan sebagai sarana untuk mencapai tujuan akhir, yaitu 
kinerja tinggi. Porter (1996:68)2 mengatakan bahwa keunggulan yang berkelanjutan tidak dapat dijamin dengan hanya memilih posisi strategis dan unik karena adanya unsur pesaing dalam hal ini.

Berdasarkan road map beberapa Perguruan Tinggi Islam termasuk UIN Maulana Malik Ibrahim Malang menjadi Perguruan Tinggi yang masuk dalam kategori World Class University menuntut persyaratan yang maksimal dan komperehensif, mencakup berbagai aspek. Hal ini tentu membutuhkan kerja keras dan profesional dari sivitas akademikanya. Namun, jika PTAIN sudah dapat masuk dalam peta dunia, atau daftar World Class University, maka ini merupakan sejarah baru bagi bangkitnya dunia pendidikan Islam. Tentu, ini bukan harapan sekelompok umat Islam Indonesia saja, namun seluruh umat Islam di dunia. Namun, pertanyaan yang dilontarkan ini oleh sebagian kalangan akan kekhawatiran lunturnya nilai-nilai Islam setelah menjadi WCU, justru sebaliknya, bahwa nilai-nilai keislaman akan terlihat nyata di ruang publik jika dapat meraih kategori international class. Untuk itu peneliti mencoba meneliti ini dilandasi dengan Maqasid Syariah.

\section{Teori Legitimasi (Legitimacy Theory)}

\section{TINJAUAN PUSTAKA}

Legitimasi masyarakat merupakan faktor strategis bagi perusahaan dalam rangka mengembangkan perusahaan ke depan. Legitimasi mengalami pergeseran sejalan dengan pergeseran masyarakat dan lingkungan. Perusahaan harus dapat menyesuaikan perubahan tersebut baik produk, metode dan tujuan. Deegan, Robin dan Tobin (2002) menyatakan legitimasi dapat diperoleh manakala terdapat kesesuaian antara keberadaan perusahaan tidak mengganggu atau sesuai dengan eksistensi system nilai yang ada dalam masyarakat dan lingkungan. Ketika terjadi pergeseran yang menuju ketidaksesuaian, maka pada saat itu legitimasi perusahaan dapat terancam. Legitimacy Theory menitikberatkan bahwa organisasi mempertimbangkan hak public secara luas, tidak hanya investor saja. Teori legitimasi menegaskan bahwa perusahaan terus berupaya memastikan bahwa mereka beroperasi dalam bingkai dan norma yang ada dalam masyarakat atau lingkungan dimana perusahaan berada, dimana mereka berusaha untuk memastikan bahwa aktivitas perusahaan diterima oleh pihak luar sebagai suatu yang "sah" (Deegan dan Gordon, 1996).

\section{RAGAM MAQASID SYARIAH}

Imam asy-Syatibi menjelaskan ada 5 (lima) bentuk maqasid syariah atau yang biasa disebut kulliyat al-khamsah (lima prinsip umum), yaitu

1. Hifdzu din (melindungi agama)

2. Hifdzu nas (melindungi jiwa)

3. Hifdzu aql (melindungi pikiran)

4. Hifdzu mal (melindungi harta)

5. Hifdzu nasab (melindungi keturunan)

Kelima maqasid tersebut di atas bertingkat-tingkat sesuai dengan tingkat mahahat dan kepentingannya.

\section{METODE RISET}

Penelitian ini dilakukan dengan menggunakan motode kualitatif. Penelitian deskriptif kualitatif merupakan penelitian yang termasuk dalam jenis penelitian kualitatif. Tujuan dari penelitian ini adalah mengungkap fakta, keadaan, fenomena, variabel dan keadaan yang terjadi saat penelitian berjalan dan menyuguhkan apa adanya. Penelitian deskriptif kualitatif menafsirkan dan menuturkan data yang bersangkutan dengan situasi yang sedang terjadi, sikap serta pandangan yang terjadi di dalam 
masyarakat, pertentangan 2 keadaan / lebih, hubungan antar variabel, perbedaan antar fakta, pengaruh terhadap suatu kondisi, dan lain-lain. Masalah yang diteliti dan diselidiki oleh penelitian deskriptif kualitatif mengacu pada studi kuantitatif, studi komparatif, serta dapat juga menjadi sebuah studi korelasional 1 unsur bersama unsur lainnya. Penelitian kualitatif merupakan metode-metode untuk mengeksplorasi dan memahami makna yang olah oleh individu atau sekelompok orang dianggap berasal dari masalah sosial. Proses penelitian kualitatif ini menggunakan desain penelitian studi kasus dalam arti penelitian difokuskan pada satu fenomena saja yang dipilih dan ingin dipahami secara mendalam, satu fenomena tersebut bisa berupa seorang pimpinan pendidikan, suatu pemrogram, suatu pemroses, satu penerapan kebijakan, satu konsep, seperti dikemukakan oleh Creswell bahwa studi kasus merupakan strategi penelitian dimana di dalamnya peneliti menyelidiki secara cermat suatu program, peristiwa, aktivitas, proses, atau sekelompok individu. Peneltian ini meneliti perguruan tinggi negeri Islam, yang apakah dalam proses kerjana mengarah ke kajian Islam itu sendiri yaitu Maqasid Sariah.

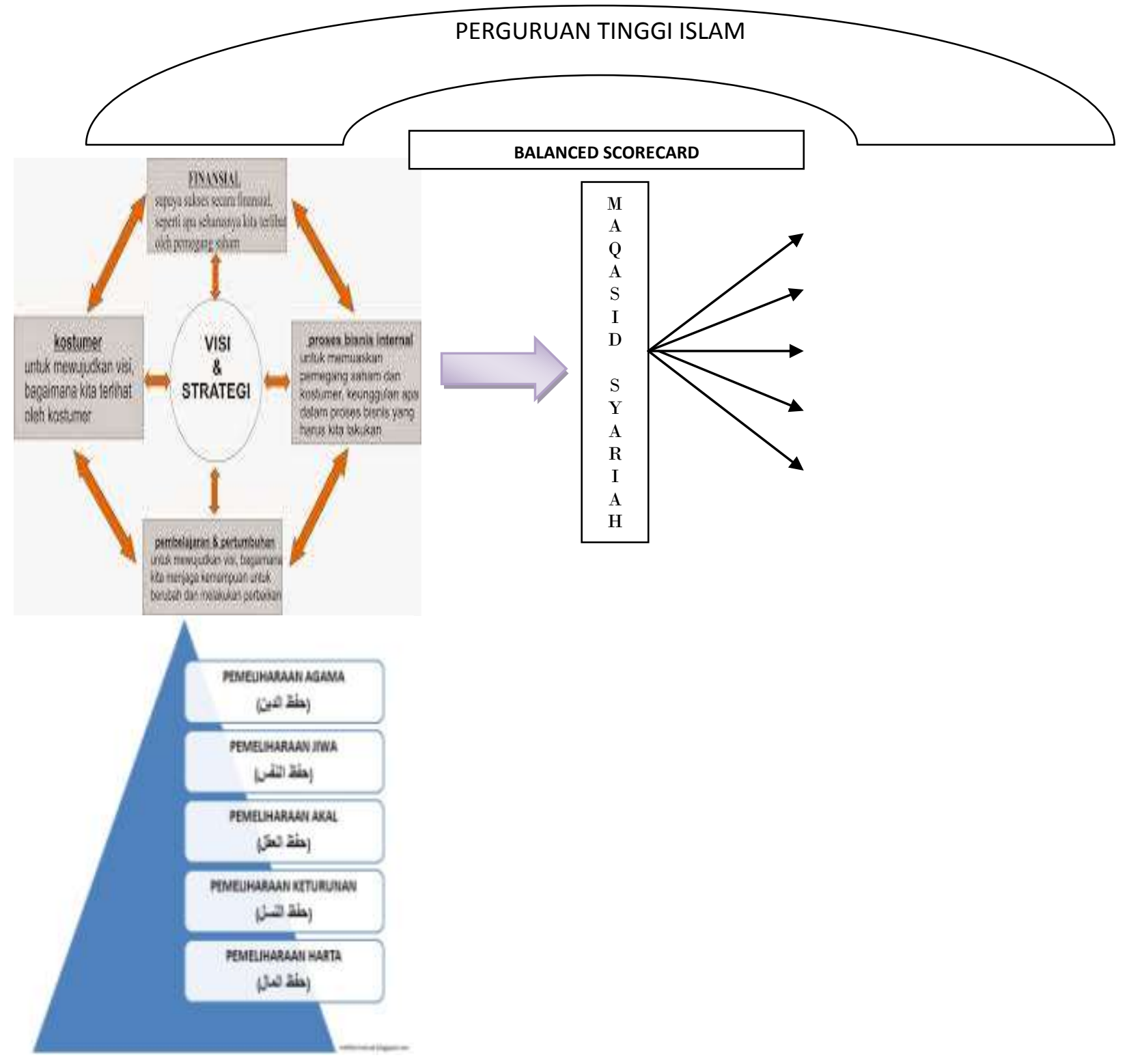


Dalam penelitian ini analisis data berpedoman pada model interaktif. Artinya analisis dilakukan secara interaktif dan berlangsung terus-menerus. Model interaktif tersebut dapat digambarkan dengan suatu kerangka yang merangkum tiga rangkaian tahap analisis, Miles dan Hubberman menjelaskan bahwa aktivitas analisis data terdiri dari tiga tahap, yaitu: mereduksi data temuan (data reduction), penyajian data dengan analisisnya (data display) dan penarikan kesimpulan (conclusion drawing/verification) yang akurat tentang penggunaan metode balanced scorecard di UIN Malang. Reduksi data merupakan proses pemilihan, pemusatan perhatian pengabstraksian, dan pentransformasian data kasar yang muncul dari catatan-cacatan tertulis dilapangan. Proses ini berlangsung selama penelitian dilakukan, dari awal sampai akhir penelitian. Pada awal, melalui kerangka konseptual, permasalahan, pendekatan pengumpulan data yang diperoleh dengan membuat ringkasan, kode, mencari tema-tema. Dalam reduksi data ini peneliti memfokuskan pada hal-hal yang penting mengenai visi, misi, strategi, tujuantujuan strategi pada penggunaan metode balanced scorecard di UIN Malang. Data yang selanjutnya disederhanakan dengan klasifikasi data dasar tema yang terbagi pada beberapa perspektif balanced scorecard yaitu fiansial, stakeholder, proses internal, dan learning \& growth. Penyajian data adalah sekumpulan informasi tersusun yang memberi kemungkinan untuk menarik kesimpulan dan pengambilan tindakan. Bentuk penyajiannya antara lain berupa teks naratif, matriks, grafik, dan bagan. Tujuannya untuk memudahkan membaca dan menarik kesimpulan. Dalam tahap ini peneliti juga melakukan display (penyajian) antar bagian - bagiannya dalam konteks yang utuh, data diklasifikasi berdasarkan tema-tema ini. Pada tahap ini peneliti menyajikan data dalam bentuk bagan dan tabel mengenai visi, misi, strategi, tujuan-tujuan strategis dan ukuran dari keempat perspektif balanced scorecard beserta ukuran strategis dari keempat perspektif balanced scorecard dan target yang ingin dicapai pada penilaian kinerja di UIN Malang. Penarikan kesimpulan/verifikasi adalah penarikan kesimpulan dari data yang telah dianalisis. Verifikasi berupa uji kebenaran terhadap makna yang muncul dari data yang telah di displaykan. Fokus peneliti pada tahap ini adalah pada abstraksi data yang tertuang dalam bagan mengenai visi, misi, strategi, ukuran-ukuran kinerja yang digunakan untuk mengukur pencapaian tujuan strategis dari keempat perspektif serta target yang ingin dicapai oleh universitas.

Melalui balanced scorecard, universitas ini bertujuan untuk memantau kinerja saat ini dan upaya untuk memberikan pengajaran, pembelajaran dan kegiatan penelitian, untuk meningkatkan layanan pelanggan, menjaga karyawan termotivasi dan meningkatkan sistem informasi (Cribb dan Hogan, 2003)19. Dalam lingkungan ini Balanced Scorecard sebagai kerangka konseptual untuk menerjemahkan misi dan tujuan menjadi satu set indicator kinerja yang didistribusikan di antara empat perspektif :

a. financial, bagaimana UIN dimata pemberi dana

b. pelanggan, bagaimana pelanggan memandang UIN

c. proses bisnis internal, apakah UIN telah bekerja dengan produktif

d. inovasi dan pembelajaran, apakah UIN telah menciptakan nilai bagi stakeholder

e. Tahap keempat, membuat strategic map dapat dibangun dengan menghubungkan strategi dan tujuan dari unit-unit dengan menggunakan hubungan sebab akibat (cause-effect relationship).

Imam asy-Syatibi menjelaskan ada 5 (lima) bentuk maqasid syariah atau yang biasa disebut kulliyat al-khamsah (lima prinsip umum), yaitu 1. Hifdzu din (pemeliharaan agama) 2.Hifdzu nas (pemeliharaan jiwa) 3. Hifdzu aql (pemeliharaan pikiran) 4. Hifdzu mal (pemeliharaan harta) 5. Hifdsu nasab (pemeliharaan keturunan) 
Kelima maqasid tersebut di atas bertingkat-tingkat sesuai dengan mashlahat dan kepentinganna. Tingkatan urgensi dan kepentingan tersebut ada 3 (tiga) ( Oni dan Adiwarman, 2015), yaitu :

- Dharuriyat, yaitu kebutuhan yang harus dipenuhi; yang jika tidak dipenuhi akan membuat kehidupan menjadi rusak.

- Hijayat, yaitu kebutuhan yang seyogiyanya dipenuhi; yang jika tidak dipenuhi akan mengakibatkan kesulitan

- Tahsinat, kebutuhan pelengkap; ang jika tidak dipenugi akan membuat kehidupan menjadi kurang nyaman

Untuk memperjelas substansi dan ragam maqasid di atas, berikut skema tentang ragam dan ruang lingkup Maqasid Syariah

Gambar 1

Kerangka Berpikir

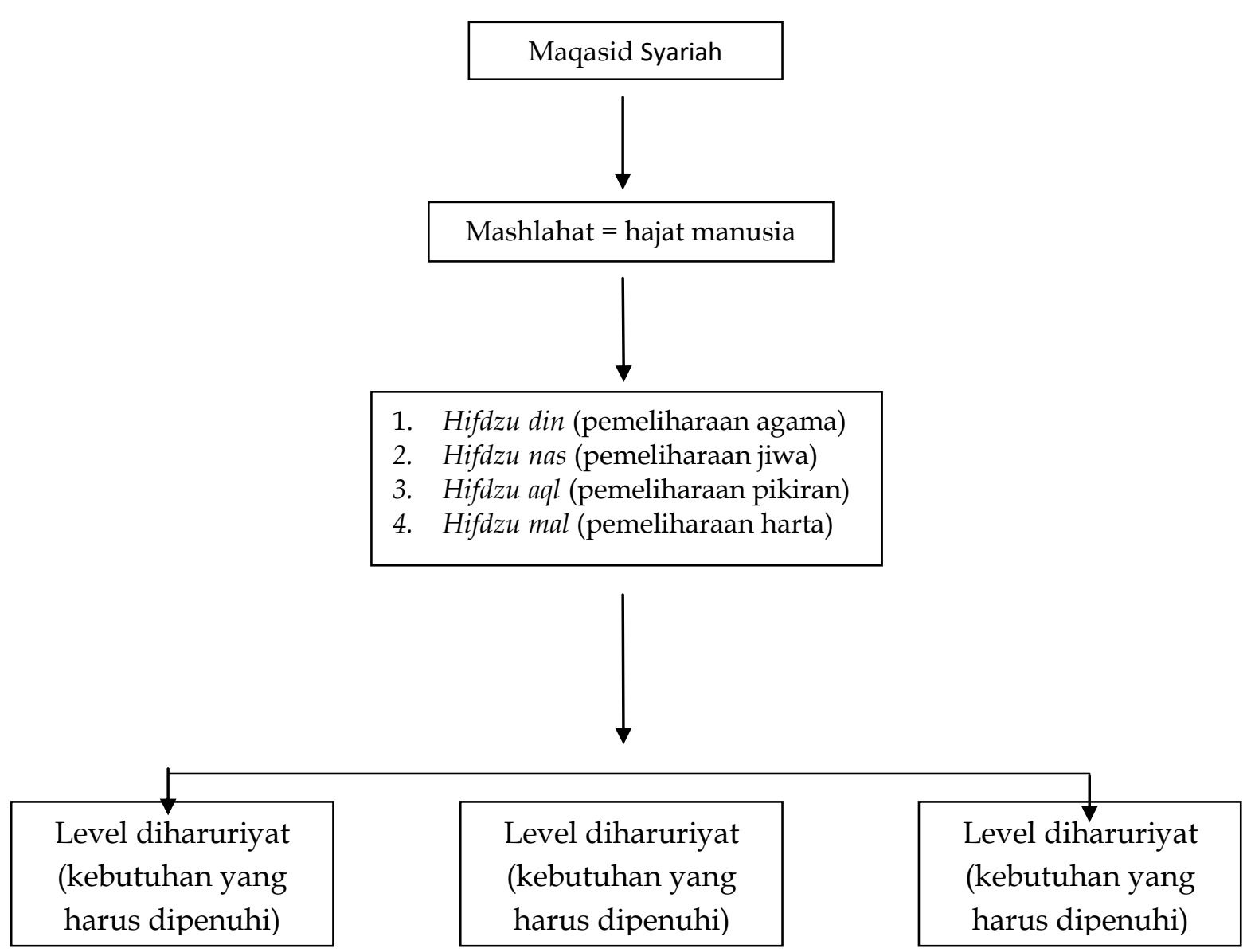

Sumber : Oni, Adiwarman, 2015

Berikutnya mengukuran kinerja bertujuan untuk meningkatkan kemajuan organisasi ke arah yang lebih baik. Untuk dapat mengukur kinerja, maka harus ditetapkan ukuran-ukuran yang sesuai untuk setiap tujuan-tujuan strategis. Indikator peragaan kunci atau KPI (Key Performance Indicator) dikembangkan berdasarkan hasil analisis kondisi Universitas Islam Negeri Maulana Malik Ibrahim Malang yang terdiri 
dari dua kelompok yaitu KPI upaya (input) yang mencakup proses/program dan KPI luaran (output).

Tabel 1

KPI (Key Performance Indicator)

\begin{tabular}{|c|c|c|c|}
\hline No. & Perspektif & $\begin{array}{c}\text { Strategic Objectives } \\
\text { Upaya (input) }\end{array}$ & $\begin{array}{c}\text { Measures } \\
\text { Luaran (output) }\end{array}$ \\
\hline 1. & Keuangan & $\begin{array}{l}\text { 1. Meningkatkan total } \\
\text { penerimaan } \\
\text { 2. Mengurangi tingkat } \\
\text { ketergantungan dari } \\
\text { dana sumbangan } \\
\text { pendidikan mahasiswa }\end{array}$ & $\begin{array}{l}\text { 1. Total Penerimaan atau } \\
\text { pertumbuhan penerimaan } \\
\text { 2. Proporsi (\%) dana sumbangan } \\
\text { mahasiswa dari total } \\
\text { penerimaan } \\
\text { 3. Proporsi dana APBN dari total } \\
\text { penerimaan } \\
\text { 4. Proporsi dana non-mahasiswa } \\
\text { dari total penerimaan } \\
\text { 5. Indeks Produktifitas } \\
\text { (Revenue/total aset) } \\
\text { 6. Rasio pendapatan pendidikan } \\
\text { per biaya layanan }\end{array}$ \\
\hline 2. & $\begin{array}{l}\text { Perspektif } \\
\text { Stakeholders }\end{array}$ & $\begin{array}{l}\text { 1. Meningkatnya kepuasan } \\
\text { mahasiswa terhadap } \\
\text { layanan akademik } \\
\text { 2. Meningkatnya kepuasan } \\
\text { dosen } \\
\text { terhadap layanan } \\
\text { administrative } \\
\text { 3. Meningkatnya kepuasan } \\
\text { stakeholder terhadap } \\
\text { layanan }\end{array}$ & $\begin{array}{l}\text { 7. Indeks Kepuasan Mahasiswa } \\
\text { 8. Indeks Kepuasan dosen } \\
\text { terhadap layanan administratif } \\
\text { 9. Peningkatan sarana dan } \\
\text { prasarana akademik: } \\
\text { - Rasio luas ruang } \\
\text { kuliah/mahasiswa } \\
\text { - Rasio ruang dosen/dosen } \\
\text { - Rasio luas lab./mahasiswa } \\
\text { 10. Jumlah kelas yang berfasilitas } \\
\text { ICT } \\
\text { 11. Indeks Kepuasan Pengguna } \\
\text { Layanan (termasuk layanan } \\
\text { bisnis) } \\
\text { 12. Jumlah layanan bisnis }\end{array}$ \\
\hline 3. & $\begin{array}{l}\text { Perspektif } \\
\text { Proses } \\
\text { Internal }\end{array}$ & $\begin{array}{l}\text { 1. Meningkatnya } \\
\text { produktifitas dosen dan } \\
\text { karyawan } \\
\text { 2. Meningkatnya kerjasama } \\
\text { dan } \\
\text { Kemitraan } \\
\text { 3. Efisiensi prosedur } \\
\text { administrative } \\
\text { 4. Meningkatnya } \\
\text { transparansi dan } \\
\text { akuntanbilitas laporan } \\
\text { keuangan } \\
\text { 5. Meningkatnya prestasi }\end{array}$ & $\begin{array}{l}\text { 13. Jumlah dosen yang melakukan } \\
\text { riset } \\
\text { 14. Jumlah publikasi dosen di jurnal } \\
\text { nasional dan internasional } \\
\text { 15. Jumlah MOU dengan pihak luar } \\
\text { 16. Jumlah laporan keuangan yang } \\
\text { sesuai DIPA } \\
\text { 17. Jumlah SOP yang } \\
\text { disempurnakan } \\
\text { 18. Kecepatan pengiriman informasi } \\
\text { 19. Kecepatan penyelesaian } \\
\text { pembuatan ijazah dan transkrip } \\
\text { 20. Tenggang waktu penerbitan }\end{array}$ \\
\hline
\end{tabular}


mahasiswa

6. Meningkatnya penggunaan system informasi

7. Terwujudnya pengendalian internal yang baik

8. Terwujudnya sistem perencanaan yang akuntabel, efisien, dan dapat dipertanggungjawabkan

9. Meningkatkan kualitas dan kuantitas mahasiswa baru

10. Meningkatnya belajar mengajar

ijazah dan yudisium

21. Jumlah Prestasi mahasiswa di tingkat nasional dan internasional

22. Angka Efisiensi Edukasi

23. Masa Studi

24. Masa Tunggu Mahasiswa

25. Persentase program studi yang terakreditasi A

26. Jumlah Kelas Bahasa Inggris

27. Nilai Rata-rata TOEFL mahasiswa

28. Jenis seleksi masuk mahasiswa

29. Rasio pendaftar dan yang diterima

proses 30. Prosentase (\%) minimal kehadiran dosen

31. Prosentase (\%) minimal kehadiran mahasiswa

32. Ketepatan waktu dalam perkuliahan

33. Kecepatan pengumuman nilai

34. Ketersediaan kurikulum dan silabus untuk setiap prodi

4. Inovasi

(Learning $\mathcal{E}$ Growth)
1. Meningkatnya kesejahteraan dosen dan staf administratif

2. Meningkatnya program pendidikan berkelanjutan bagi dosen dan staf administrative

3. Meningkatnya pelatihan inovasi pembelajaran bagi dosen

4. Meningkatnya pelatihan metoda riset

5. Meningkatnya pelatihan penggunaan fasilitas bagi dosen dan staf administrative

6. Meningkatnya dosen bergelar S-3
35. Jumlah pendidikan dan pelatihan yang dilakukan

36. Jumlah beasiswa bagi dosen untuk studi lanjut

37. Jumlah peserta pelatihan

38. Jumlah jenis pelatihan yang dilakukan 
Tabel 2. Indikator Sasaran dan target Pencapaian

\begin{tabular}{|c|c|c|c|c|c|}
\hline \multirow[t]{2}{*}{ No } & \multirow[t]{2}{*}{ Indicator Sasaran } & \multicolumn{4}{|c|}{ Target Pencapaian } \\
\hline & & 2012 & 2013 & 2014 & 2015 \\
\hline 1. & $\begin{array}{l}\text { Persentase APBN dari total } \\
\text { pendapatan }\end{array}$ & $30 \%$ & $29 \%$ & $28 \%$ & $27 \%$ \\
\hline 2. & $\begin{array}{l}\text { Persentase pendapatan non- } \\
\text { sumbangan mahasiswa atas total } \\
\text { pendapatan }\end{array}$ & $30,40 \%$ & $33,45 \%$ & $35,60 \%$ & $37,20 \%$ \\
\hline 3. & $\begin{array}{l}\text { Persentase dana sumbangan } \\
\text { mahasiswa dari total pendapatan }\end{array}$ & $35,60 \%$ & $34,56 \%$ & $33,33 \%$ & $30,92 \%$ \\
\hline
\end{tabular}

Analisis penerapan maqasid syariah dalam kaitannya dengan hasil KPI dan dikaitan dengan hasil penelitian yang telah dilakukan terdapat beberapa hal yang dapat disimpulkan, diantaranya:

1. Sistem penilaian kinerja pada UIN Maulana Malik Ibrahim Malang memiliki strategic objectives diantaranya :

a) strategic objectives perspektif finansial yaitu kemampuan mendapatkan dana dan efisiensi biaya;

b) strategic objectives perspektif stakeholder yaitu kepercayaan stakeholders kepada UIN Maulana Malik Ibrahim Malang, kepuasan \& kebanggaan mahasiswa terhadap UIN Maulana Malik Ibrahim Malang;

c) strategic objectives perspektif proses internal yaitu unit bisnis UIN Maulana Malik Ibrahim Malang, proses prosedur \& kebijakan, system keuangan dan pelaporan, internal control \& pengukuran kinerja, kualitas riset \& pengabdian kepada masyarakat;

d) strategic objectives learning $\mathcal{E}$ growth yaitu pembangunan SIM, peningkatan profesionalisme SDM, peningkatan kualitas sarana \& prasarana.

2. Pemahaman strategi UIN Maulana Malik Ibrahim Malang menghasilkan 21 sasaran strategis pada keempat perspektif Balanced Scorecard dan 38 KPI yang akan digunakan sebagai ukuran didalam scorecard. Jumlah ukuran yang diberikan pada perspektif pelanggan berimbang dengan ukuran pada perspektif keuangan yaitu sebesar 15\%, dirata-rata, dimana UIN Maulana Malik Ibrahim Malang menitikberatkan pada ukuran proses internal sebesar rata-rata $28 \%$ untuk memuaskan pelanggan dan perspektif pertumbuhan \& pembelajaran sebesar rata-rata $14 \%$.

3. Hasil perancangan dan pengukuran ini diperoleh berbagai rumusan balanced scorecard UIN Maulana Malik Ibrahim Malang yang mencakup tujuan, ukuran, sasaran dan inisiatif strategis yang tergambar pada Peta Strategi dan Key Performance Indicator (KPI).

Tabel 3

Analisis KPI berbasis Maqasid Syariah

\begin{tabular}{|c|c|c|}
\hline Perspektif & Perspektif Maasid Syariah & Penjabaran \\
\hline 1. Keuangan & $\begin{array}{l}\text { 1. Hifdzu din (pemeliharaan } \\
\text { agama) } \\
\text { 2. Hifdzu nas (pemeliharaan } \\
\text { jiwa) } \\
\text { 3. Hifdzu aql (pemeliharaan } \\
\text { pikiran) } \\
\text { 4. Hifdzu mal (pemeliharaan }\end{array}$ & $\begin{array}{l}\text { Mengajarkan Islam lebih dalam } \\
\text { kepada peserta secara Internal } \\
\text { dan Eksternal, meningkatkan } \\
\text { ukhuwa Islamiyyah dan amal jamai. } \\
\text { Meningkatkan persebaran } \\
\text { dakwah Islam. }\end{array}$ \\
\hline
\end{tabular}




\begin{tabular}{|c|c|c|c|}
\hline \multicolumn{4}{|c|}{ harta) } \\
\hline 2. & $\begin{array}{l}\text { Perspektif } \\
\text { Stakeholders }\end{array}$ & $\begin{array}{l}\text { 1. Hifdzu din (pemeliharaan } \\
\text { agama) } \\
\text { 2. Hifdzu nas (pemeliharaan } \\
\text { jiwa) } \\
\text { 3. Hifdzu aql (pemeliharaan } \\
\text { pikiran) } \\
\text { 4. Hifdzu mal (pemeliharaan } \\
\text { harta) }\end{array}$ & $\begin{array}{l}\text { Berkontribusi nyata dan langsung } \\
\text { kepada masyarakat, } \\
\text { meningkatkan kepedulian social } \\
\text { sehingga tidak menadi pemimpin } \\
\text { yang elitis, dan membangun } \\
\text { kedekatan emosional antara } \\
\text { dosen dan masyarakat sebagai } \\
\text { stakeholder utama. }\end{array}$ \\
\hline 3. & $\begin{array}{l}\text { Perspektif } \\
\text { Proses Internal }\end{array}$ & $\begin{array}{l}\text { 1. Hifdzu din (pemeliharaan } \\
\text { agama) } \\
\text { 2. Hifdzu nas (pemeliharaan } \\
\text { jiwa) } \\
\text { 3. Hifdzu aql (pemeliharaan } \\
\text { pikiran) } \\
\text { 4. Hifdzu mal (pemeliharaan } \\
\text { harta) }\end{array}$ & $\begin{array}{l}\text { Membangun pemahaman Islam } \\
\text { yang komprehensif, moderat, } \\
\text { inklusif, dan visioner terhadap } \\
\text { karyawan dan dosen sehingga } \\
\text { dapat terjalin misi sebagai } \\
\text { Rahmatan lil alamin. }\end{array}$ \\
\hline 4. & $\begin{array}{l}\text { Inovasi } \\
\text { (Learning } \mathcal{E} \\
\text { Growth) }\end{array}$ & $\begin{array}{l}\text { 1. Hifdzu din (pemeliharaan } \\
\text { agama) } \\
\text { 2. Hifdzu nas (pemeliharaan } \\
\text { jiwa) } \\
\text { 3. Hifdzu aql (pemeliharaan } \\
\text { pikiran) } \\
\text { 4. Hifdzu mal (pemeliharaan } \\
\text { harta) }\end{array}$ & $\begin{array}{l}\text { Menyiapkan mahasiswa secara } \\
\text { fisik, intelektual, emosional, dan } \\
\text { spiritual di Ma'had (asrama). }\end{array}$ \\
\hline
\end{tabular}

Sumber : hasil wawancara, data diolah 2016

\section{KESIMPULAN}

Untuk mengelola keuangan secara mandiri dan fleksibel harus dilakukan dengan mengedepankan produktivitas, efisiensi dan efektivitas. Pengelolaan keuangan melalui pola Badan Layanan Umum (BLU) dapat memberikan keleluasaan untuk menggali dan menggunakan sumberdaya keuangan yang bersumber dari hasil pelayanan. Kerjasama institusi dengan masyarakat dan lembaga-lembaga lain di dalam maupun di luar negeri berjalan dengan baik sehingga dapat meningkatkan citra UIN Maulana Malik Ibrahim Malang. Hasil-hasil penelitian yang sangat banyak dapat dimanfaatkan untuk memperkaya bahan ajar dan pembangunan masyarakat. Sehingga hasil penelitian yang telah dipublikasikan dan dipatenkan, dapat memberikan konstribusi dalam membangun citra dan revenue generation bagi UIN Maulana Malik Ibrahim Malang.

Evaluasi dan penanganan secara khusus untuk hal di atas sangat dibutuhkan di masa yang akan datang. Organisasi dan unit UIN Maulana Malik Ibrahim Malang yang terkait dengan pengembangan Pusat Bisnis yang diinisiasi adalah jawaban untuk menyelesaikan problematika ini.

Ketercukupan infrastruktur perangkat keras dan sistem jaringan masih belum secara optimal dimanfaatkan, sehingga masih terdapat kapasitas tersisa yang sebaiknya segera dimanfaatkan. Langkah konsolidasi, sosialisasi dan pelatihan-pelatihan nampaknya perlu 
ditingkatkan dan dicarikan terobosan agar dapat dipercepat demi kemajuan UIN di masa datang.

Pengembangan manajemen dalam hal ketersediaan sumber daya untuk support teknis perlu

ditingkatkan sehingga mampu memberikan pelayanan dalam hal pengembangan dan operasional secara optimal dengan memanfaatkan sarana prasarana yang ada.

\section{DAFTAR PUSTAKA}

Balanced Scorecard "Alat Manajemen Kontemporer Untuk pelipatganda Kinerja Keuangan Perusahaan". PT Salemba Emban Patria. Edisi ke-1, 2000.

Cribb, G. \& Hogan, C. Balanced Scorecard: linking strategic planning to measurement and communication, Information Service Paper, Bond University, Australia, available at: http:/ / epublications.bond.edu.au/cgi/viewcontent.cgi?article=1006\&context=libr ary_pubs2003.

Fred R, David. Manajemen Strategis: Konsep. Edisi Ketujuh. Pearson Education Asia Pte. Dan PT Perhallindo, Jakarta,2002.

Hafner, K., A. Partnership for performance: The Balanced Scorecard put to the test at the University of California. Director, Business Initiatives, University of California Office of the President,1998.

J.A Pierce dan R.B Robinson. Manajemen Strategis: Formulasi, Implementasi dan Pengendalian. Edisi Pertama. Penerbit Binarupa Aksara, Jakarta, 1997.

J.A.F, Stones dan Freeman, R.E. Manajemen. Edisi Kelima Intermedia, Jakarta, 1994.

Kaplan \& Norton, D.P, The Balanced Scorecard-Translating Strategy Into Action Harvard Business School Press, Boston,1996.

Kaplan S Robert and David P Norton, The Balanced Scorecard. Boston: Harvard Business Review School Press.

Kaplan S.Robert dan David P.Norton,The Balance Scorecard-Measures that Drive Performance . Harvard Business Review, edisi Januari-Februari 1992.

Kaplan S.Robert dan David P.Norton. Strategy Maps: Converting Intangible Assets Into Tangible Outcomes. Harvard Business School Publishing, 2004.

Kaplan, Robert S. dan David P. Norton. Using the Balanced Scorecard as a Strategic Management System. Harvard Business Review, 1996.

Kaplan, Robert S dan David Norton. Having Trouble With Your strategy? Then Map It. Harvard Business Review, January-February,2000.

Kaplan, Robert S. dan David P. Norton. Measuring the Strategic Readiness of Intangible Assets. Harvard Business Review. 2004

Kaplan, Robert S. dan David P. Norton. Putting the Balanced Scorecard to Work. Harvard Business Review. January-February. 1993

Kaplan, S.Robert dan David P.Norton. Strategy Maps: Converting Intangible Assets Into Tangible Outcomes. Harvard Business School Publishing, 2004.

Kaplan, S.Robert dan David P.Norton, The Strategy Maps Focused Organization. Boston: Harvard Business School Press Boston, 2001.

Karim Bisnis Consulting Indonesia, Kajian Pengembangan Ekonomi dan Keuangan Syariah, disampaikan kepada Kementrian Pembangunan Nasional/Badan Perencanaan Pembangunan Nasional (BAPENAS).

Mulyadi, dan Johny Setiawan. Sistem Perencanaan dan Pengendalian Manajemen: Sistem Pelipatgandaan Kinerja Perusahaan, Edisi Satu: Aditya Medika,Yogyakarta, 1999.

Miles Mathew A. And A.Michael Hubberman. Qualitative Data Analysis. Sage Publication Inc, 1984. 
Moleong, Lexy. Metode Penelitian Kualitatif. Bandung : Remaja Rosda Karya,2007.Simons, Robert. Performance Measurement of Control System for Implementing Strategy. Prentice-Hall,2000.

Oni, Adiwarman. Maqasid Bisnis \& Keuangan Islam Sintesis Fiqih dan Ekonomi. Penerbit Rajagrafindo Persada, 2015.

Sistem Terpadu Pengelolaan Kinerja Personal Berbasis Balanced Scorecard. Penerbit : UPP Sekolah Tinggi Ilmu Manajemen YKPN, 2007.

Thomas L.Wheelen and J.David Hunger. Strategic Management and Business Policy, 8th edition, Prentice Hall, 2002.

Yin, Robert K. Case Study Research: Design and Methods. New Delhi: Sage Publications, 2003. 